\title{
JANGJAWOKAN PARANTI DANGDAN: RAHASIA PESONA GADIS DESA KARANGJAYA KABUPATEN PANGANDARAN
}

\author{
Yeni Yulia Andriani ${ }^{1}$, Silvy C. Adelia ${ }^{2}$ \\ ${ }^{1}$ Universitas Papua \\ Jln. Gunung Salju Amban Manokwari-Papua Barat \\ y.andriani@unipa.ac.id \\ ${ }^{2}$ Universitas Negeri Surabaya \\ Jl. Lidah Wetan Lakarsantri Surabaya-Jawa Timur \\ silvyadelia@unesa.ac.id
}

\begin{abstract}
ABSTRAK
Artikel ini bertujuan mendeskripsikan pertunjukan dan transmisi Jangjawokan Paranti Dangdan. Jangjawokan Paranti Dangdan merupakan sastra lisan dalam bentuk mantra yang dimiliki masyarakat Sunda di Desa Karangjaya Kabupaten Pangandaran. Pada saat ini, Jangjawokan Paranti Dangdan masih eksis digunakan oleh perempuan Desa Karangjaya dalam kehidupan sehari-hari. Berdasarkan latar belakang tersebut, penelitian ini dilakukan untuk (1) mengetahui pertunjukan Jangjawokan Paranti Dangdan; dan (2) transmisi Jangjawokan Paranti Dangdan di kalangan perempuan Desa Karangjaya. Metode yang digunakan dalam penelitian adalah metode deskriptif dengan tujuan mendeskripsikan objek yang diteliti berdasarkan fakta yang diperoleh. Sumber data dari penelitian ini adalah Jangjawokan Paranti Dangdan dan informasi-informasi yang diperoleh secara langsung dari informan yang merupakan pewaris sekaligus pelestari mantra dalam lingkaran kekerabatan. Penelitian ini menggunakan perspektif naturilistik dengan teori transmisi Parry-Lord. Teori transmisi digunakan untuk mengungkap pertunjukan dan pewarisan sastra lisan. Hasil penelitian ini mengungkap pertunjukan mantra di hadapan pewaris dan transmisi mantra yang meliputi syarat-syarat pewaris dan ritual pewarisan.
\end{abstract}

Kata kunci: mantra, pertunjukan, transmisi, jangjawokan paranti dangdan

\section{ABSTRACT}

This article aims at describing the performance as well as transmission of Jangjawokan Paranti Dangdan. Jangjawokan Paranti Dangdan can be considered as an oral literature in the form of spell in Karangjaya Village, Pangandaran District. Jangjawokan Paranti Dangdan is still used by women in Karangjaya Village today. Based on this background, this study was conducted to (1) determine the performance of Jangjawokan Paranti Dangdan; and (2) the transmission of Jangjawokan Paranti Dangdan among women in Karangjaya Village. The method used in this research is descriptive method with the purpose of describing the object being examined using the collected data. The data source of this research is the Jangjawokan Paranti Dangdan and the information obtained directly from an informant who has inherited and conserved the spell among her kinship. This research uses naturalistic perspective combined with ParryLord's transmission theory. The transmission theory is used to reveal the performance and 
the transmission of oral literature. The results of this study show the spell performance in front of the heir as well as the spell transmission that include the terms and rituals of inheritance.

Keywords: Spell, Performance, Transmission, Jangjawokan Paranti Dangdan

\section{PENDAHULUAN}

Khazanah sastra daerah dan sastra lisan di Indonesia sangat kaya akan tradisi puisi, khususnya jenis puisi formulaik. Para ahli sastra umumnya sependapat bahwa bentuk awal (prototype) puisi Indonesia adalah mantra (Taum, 2011: 50). Hal tersebut selaras dengan pernyataan yang dikemukakan Dananjaya (1991: 46) bahwa kepercayaan rakyat yang berupa mantra-mantra tergolong ke dalam bentuk puisi rakyat.

Menurut Junus (dalam Ramadhan, 2016: 2), ciri-ciri mantra adalah sebagai berikut:

1. Di dalam mantra terdapat rayuan dan perintah;

2. Mantra mementingkan keindahan bunyi atau permainan bunyi;

3. Mantra menggunakan kesatuan pengucapan;

4. Mantra merupakan sesuatu yang utuh, yang tidak dapat dipahami melalui bagianbagiannya;

5. Mantra sesuatu yang tidak dipahami oleh manusia karena merupakan sesuatu yang serius;

6. Di dalam mantra terdapat kecenderungan esoteris (khusus) dari kata-katanya).

Mantra dikenal masyarakat Indonesia umumnya dan masyarakat Sunda khususnya sebagai rapalan ucapan dalam bahasa tertentu dengan maksud dan tujuan tertentu. Mantra merupakan puisi lisan yang bersifat magis, magis di sini berarti sebagai sesuatu yang digunakan manusia untuk mencapai tujuan-tujuannya dengan cara-cara yang istimewa. Perilaku magis disebut juga sebagai perilaku yang dilakukan untuk mencapai suatu maksud tertentu yang dipercaya manusia ada di alam supranatural (Rusyana, 1970: 3).

Kepercayaan terhadap alam supranatural berdampak pula pada keyakinan terhadap mantra. Masyarakat Sunda meyakini bahwa mantra dapat memberikan manfaat bagi penggunanya, sehingga mantra begitu terikat dengan segala aktivitas keseharian masyarakat. Rusyana (1970: 5) menyatakan bahwa keberadaan mantra di masyarakat sangat bergantung pada tingkat kepercayaan masyarakat. Kepercayaan terhadap adanya jiwa yang menguasai alam dapat berpengaruh terhadap kehidupan manusia dan alam sekitar merupakan dasar adanya mantra yang digunakan masyarakat. Masih ada beberapa kelompok masyarakat di Indonesia yang kuat kepercayaannya terhadap mantra. Biasanya mantra-mantra yang dimiliki tersebut menggunakan bahasa daerah masing-masing dan ada pula yang dipengaruhi oleh bahasa tertentu. Pada umumnya mantra digunakan sebagai doa untuk penolak bala, pemikat, penjemput rezeki, dan sebagainya.

Desa Karangjaya yang masuk bagian wilayah Kecamatan Parigi Kabupaten Pangandaran Provinsi Jawa Barat merupakan salah satu tempat di Indonesia yang masih cukup kuat kepercayaannya terhadap mantra. Tradisi bermantra ini diwariskan secara turun temurun dalam lingkaran hubungan darah, yaitu dari anggota keluarga yang dianggap tua terhadap yang lebih muda seperti ibu ke anak perempuan, ayah ke anak laki-laki, maupun 
nenek ke cucu. Ada pun pewarisan mantra terhadap orang di luar hubungan kekerabatan "secara sukarela" yang diketahui berdasarkan penjelasan informan jarang terjadi karena bersifat rahasia dan sangat pribadi.

Dalam pewarisannya, pemilik mantra tidak bisa sembarangan mewariskan kemampuan bermantra yang dimilikinya kepada siapa saja. Pemilik mantra hanya mewariskan mantra kepada orang yang memang layak untuk mewarisinya. Hal tersebut selaras dengan pernyataan Muhazetty (2017: 3) bahwa mantra sebagai karya sastra yang diwariskan kepada orang yang berhak dan mengerti akan kegunaannya, yang masih dipercayai masyarakat sebagai kebutuhan penunjang kehidupan agamanya dijalani secara sungguh-sungguh.

Merapalkan mantra dapat dilakukan oleh siapa saja, baik orang yang memiliki kemampuan magis seperti dukun dan pawang, maupun orang-orang secara umum yang mempercayainya. Dukun merapalkan mantra biasanya atas permintaan atau pesanan orang lain sebagai salah satu upaya menyelesaikan masalah maupun menyembuhkan penyakit. Sedangkan mantra yang dituturkan orang-orang secara umum merupakan mantra bersifat pribadi seperti mantra berdandan, mantra pemikat, mantra perlindungan diri, mantra pekerjaan, dan mantra bepergian.

Mantra dalam masyarakat Sunda terbagi menjadi beberapa bagian, yaitu ajian, asihan, jangjawokan, singlar, rajah, dan jampe (Rusyana, 1970: 11). Selain itu, Nazriani (2012: 41) pun menggolongkan mantra berdasarkan isinya, yaitu mantra pengampunan, mantra kutukan, mantra keberkahan pada upacara tertentu, mantra obat-obatan, mantra untuk mendapatkan kekebalan atau kekuatan, mantra untuk mendapatkan daya pengasih, pemanis, atau penggila, dan mantra untuk menimbulkan rasa benci.

Berdasarkan penjelasan di atas, mantra yang diwariskan secara turun temurun dalam lingkaran kekerabatan di Desa Karangjaya termasuk ke dalam jangjawokan. Jangjawokan adalah mantra yang berkembang dalam masyarakat Sunda yang berfungsi sebagai penghantar doa dan harapan dalam setiap aktivitas keseharian. Menurut Rusyana (1970: 12), dalam masyarakat tradisional jangjawokan tidak hanya dianggap sebagai rangkaian kata-kata saja namun dianggap bagian dari ritual yang mengawali, menyertai, dan mengakhiri berbagai aktivitas. Hal tersebut terlihat dari banyaknya jangjawokan yang disesuaikan dengan aktivitas penutur. Misalnya, Jangjawokan Paranti Mandi (untuk mandi), Jangjawokan Paranti Nyisiran (menyisir rambut), dan sebagainya. Jangjawokan yang eksis di tengah lingkaran kekerabatan Desa Karangjaya tidak dikomersilkan seperti halnya dukun.

Mantra maupun puisi-puisi magis lainnya tersebar di Indonesia, terutama di pedesaan. Oleh karena itu, tentu telah banyak peneliti yang mengangkat hal tersebut sebagai objek kajiannya. Kebanyakan peneliti secara umum mengkaji mantra dari segi struktur teks, fungsi, dan makna. Ada pun penelitian mengenai jangjawokan di Desa Karangjaya difokuskan pada Jangjawokan Paranti Dangdan (Jangjawokan untuk Berdandan) dari segi performance (pertunjukan) dan transmisi (prosedur pewarisan). 
Selain itu, Jangjawokan Paranti Dangdan di Desa Karangjaya belum pernah diteliti sebelumnya.

Penelitian ini menggunakan teori sastra lisan yang dikemukakan Parry-Lord. Taum (2011: 100) menuliskan bahwa teori Parry-Lord tentang penciptaan sastra lisan mencakup aspek-aspek formula dan ungkapan formulaik, tema-tema atau kelompok gagasan, dan prosedur pewarisan. Ada pun teori sastra lisan Parry-Lord dalam penelitian ini difokuskan pada prosedur pewarisan atau transmisi.

Konsep transmisi dapat dikatakan paralel dengan konsep memori dalam kaitannya sebagai sebuah upaya untuk penurunan tradisi lisan. Memori atau repertoar memiliki dua buah unsur yaitu unsur aktif dan unsur pasif. Proses penurunan sastra lisan diawali dengan pertunjukan (performance). Unsur aktif lebih terfokus pada proses memori, yang dengan bekal kreativitas memungkinkan seseorang untuk merekonstruksi atau mereorganisasi terhadap pengetahuan sebelumnya. Sementara itu, unsur pasif berkaitan dengan penyimpanan memori kata per kata yang berarti lebih terfokus pada isi memori (Finnegan, 1992:114-115).

Performance juga berkaitan dengan trasmisi. Transmisi yang bersifat aktif akan terfokus pada proses transmisi yang berarti melibatkan kreativitas untuk merekonstruksi sastra lisan yang diketahui sebelumnya. Transmisi yang bersifat pasif akan terfokus pada isi transmisi dengan cara menyimpannya sesuai dengan apa adanya (kata per kata), sebagaimana sesuatu yang bersifat given. Performance atau proses pertunjukan adalah saat penciptaan sastra lisan itu sendiri. Hal tersebut disebabkan dalam proses pertunjukan tersebut terdapat bagaimana seorang penyanyi atau penyampai atau penutur sastra lisan terpengaruh dengan keadaan di sekitar mereka, terutama penonton (Lord, 1981:13-14).

\section{METODE}

Metode yang digunakan dalam penelitian ini adalah metode deskriptif dengan tujuan mendeskripsikan objek yang diteliti berdasarkan fakta yang diperoleh, yaitu Jangjawokan Paranti Dangdan dari segi performance dan transmisi.

Penelitian ini menggunakan perspektif naturalistik. Menurut Endraswara (2009: 86), penelitian folklor secara naturalistik merupakan upaya pemahaman fenomena sosial budaya dari sisi si pelaku sendiri. Hal ini tidak berarti hanya memanfaatkan data lisan saja. Keakuratan data dapat ditunjang dari berbagai sumber data. Biasanya penelitian naturalistik folklor memanfaatkan pendekatan emik, bukan etik. Pendekatan emik menengarai bahwa folklor perlu diungkap dari sisi pelaku. Secara naturalistik penelitian folklor bertujuan mengetahui aktualitas, realitas sosial dan persepsi manusia melalui pengakuan mereka, yang mungkin tidak dapat diungkap melalui penonjolan pengukuran formal atau pertanyaan penelitian yang telah dipersiapkan terlebih dahulu.

Penelitian folklor naturalistik dilakukan secara apa adanya (Endraswara, 2009: 87). Tindakan dan kata-kata pemilik folklor yang dijadikan dasar pemaknaan. Data di lapangan akan "berbicara", sehingga peneliti tinggal mengaitkan satu sama lain. Makna adalah 
realitas. Makna folklor adalah milik kolektif. Peneliti folklor tinggal membahasakan ulang ide, pemikiran, dan pandangan mereka.

Sumber data yang digunakan dalam penelitian berupa Jangjawokan Paranti Dangdan dan informasi-informasi yang diperoleh secara langsung dari informan yang merupakan pewaris sekaligus pelestari mantra dalam lingkaran kekerabatan. Informan tersebut berpedoman pada kriteria-kriteria yang telah ditentukan serta hasil pengamatan penggunaan mantra di lapangan. Kriteria-kriteria tersebut yaitu informan harus penduduk asli Desa Karangjaya, pemilik Jangjawokan Paranti Dangdan (penyampai dan pewaris), sehat jasmani dan rohani, serta mampu berkomunikasi dengan baik.

Teknik pengumpulan data dalam penelitian ini adalah wawancara dan perekaman. Wawancara digunakan untuk memperoleh data tambahan mengenai performance (pertunjukan) dan transmisi (pewarisan) Jangjawokan Paranti Dangdan, sedangkan perekaman untuk merekam jangjawokan yang diucapkan secara lisan oleh informan.

\section{HASIL DAN PEMBAHASAN}

Desa Karangjaya terletak di Kecamatan Parigi, tepatnya 5 kilometer dari pusat ibukota Kabupaten Pangandaran. Letaknya yang tidak terlalu jauh dari pusat kota dan dijangkau oleh jaringan seluler yang cukup baik tidak menjadikan wilayah ini disebut terisolir. Kemudahan transportasi, penyebaran informasi, dan perdagangan cukup dirasakan manfaatnya oleh penduduk desa. Angkutan pedesaan, ojek online, dan bus antarkota cukup mudah diakses untuk moda transportasi sehari-hari. Meskipun jarak yang ditempuh ke pasar tradisional terdekat sekitar 5 kilometer penduduk Desa Karangjaya tidak merasa keberatan karena untuk memenuhi kebutuhan sehari-hari cukup mengandalkan hasil tani di lahan sendiri dan penjual keliling yang menjajakan bahan pangan, peralatan rumah tangga, pakaian, obat-obatan herbal, hingga kosmetik.

Kemudahan-kemudahan inilah yang juga dinikmati oleh generasi muda sekaligus berdampak pada gaya hidup. Selera berpenampilan, salah satunya. Gadis-gadis Desa Karangjaya mengetahui mode pakaian terbaru, mengenal rias wajah (makeup) modern, dan banyak di antaranya yang rutin menggunakan rangkaian perawatan wajah (skincare) layaknya gadis-gadis kota.

Bagi perempuan, kecantikan merupakan aset berharga. Kecantikan yang dimaksud bukan hanya kecantikan dari luar saja melainkan lengkap dengan kecantikan dari dalam (inner beauty). Kedua kecantikan ini digunakan perempuan dalam setiap aspek kehidupannya untuk ragam kepentingan : kepuasan pribadi, pergaulan sehari-hari, karier, hingga menarik perhatian lawan jenis.

Menurut penuturan informan, cantik rupa dan berpakaian yang pantas saja tidak cukup, apalagi bagi seorang gadis. Ceuk kolot baheula awewe mah ulah sok saborod, kudu boga jampe pamake (kata nenek moyang perempuan itu jangan terlalu polos, harus memiliki pegangan). Jampe pamake atau pegangan yang dimaksud adalah hal bersifat 
magis. Jampe pamake yang berupa Jangjawokan Paranti Dangdan bukan pelet maupun ilmu hitam yang merugikan orang lain. Hal tersebut tampak dari isi Jangjawokan Paranti Dangdan yang mengandung unsur ketuhanan. Setiap jangjawokan yang dikaji dalam penelitian ini diawali dengan bacaan ta'awudz (permohonan perlindungan diri kepada Allah dari kejahatan setan) dan basmallah (menyebut nama Allah) seperti halnya adab membaca kitab suci Al Quran. Pemilik jangjawokan sadar akan eksistensi dzat yang Maha Kuasa, sehingga melalui larik demi larik puisi magis tersebut mengharapkan kebaikan dan perlindungan dari Tuhan, bukan perlindungan dari hal selain Tuhan. Manusia menyadari adanya dunia transenden, yaitu dunia tempat sesuatu yang memiliki kekuasaan di atas dan di luar jangkauan manusia. Oleh karena itu, pada bagian penutup jangjawokan terdapat kalimat ku kersaning Allah (atas kehendak Allah). Pemilik jangjawokan tersebut yakin bahwa segala sesuatu yang terjadi di dunia atas kuasa Tuhan.

Jangjawokan Paranti Dangdan berfungsi membangkitkan pesona diri, menimbulkan kasih dari orang lain, sekaligus menangkal magic pembawa keburukan yang bersifat ringan. Maksudnya ringan karena tidak mematikan. Magic pembawa keburukan ini berupa mantra atau jampi-jampi yang dikirimkan kepada korbannya karena tidak senang, merasa tersaingi, maupun sebab lain. Misalnya untuk menjadikan orang lain jijik pada korban (dipikageuleuh) dan tidak disukai (dipikaceuceub). Oleh karena itu, bagi para gadis di Desa Karangjaya skincare dan berpakaian bagus hanya bersifat ragawi, tidak bisa dijadikan perisai diri.

Jangjawokan Paranti Dangdan terdiri dari tiga tahap sesuai dengan urutan seorang gadis berdandan, yaitu mengenakan pakaian, merias wajah, dan menata rambut. Tiga tahap berdandan ini sedikitnya ada lima mantra yang harus diucapkan, yakni Jangjawokan Paranti Diacuk, Jangjawokan Wedak Wangi, Jangjawokan Sisir Suri, Jangjawokan Rambut Suci, dan Jangjawokan Paranti Dicucuk Sanggul.

\section{(1) Performance Jangjawokan Paranti Dangdan (Jangjawokan untuk Berdandan)}

Albert B. Lord menyatakan bahwa performance (pertunjukan) erat kaitannya dengan transmisi (pewarisan). Performance adalah saat penciptaan sastra lisan itu sendiri. Hal tersebut disebabkan dalam proses pertunjukan terdapat bagaimana seorang penyanyi atau penyampai atau penutur sastra lisan terpengaruh dengan keadaan di sekitar mereka, terutama penonton.

Pembahasan jangjawokan pada penelitian ini menggunakan istilah "penyampai" dan "pemilik" untuk menandai pelaku sekaligus orang yang mewariskan jangjawokan karena pengucapan jangjawokan tidak didendangkan maupun dituturkan seperti cerita rakyat. Adapun performance dalam penelitian ini menitikberatkan pada bagaimana seorang pengguna mantra merapalkan jangjawokan beserta adab-adabnya, baik untuk dirinya sendiri maupun ketika mempertunjukkannya di hadapan calon pewaris. Pewaris dalam konteks transmisi Jangjawokan Paranti Dangdan berperan ganda sebagai "penonton" karena hanya pewarislah yang menyaksikan performance penyampai.

Jangjawokan Paranti Dangdan dirapalkan secara private untuk kepentingan pribadi. Kelima mantra yang diucapkan sesuai urutan berdandan memiliki adab-adabnya 
tersendiri dan tidak boleh terlewatkan. Selain itu, kata per kata dalam jangjawokan tidak boleh diubah sembarangan, kecuali bila ada hal yang kurang relevan dipakai pada masa kini. Penyampai maupun pewaris jangjawokan harus mengingatnya dengan sempurna.

A. Jangjawokan Paranti Diacuk (Mantra untuk Berpakaian)

Tabel 1. Jangjawokan Paranti Diacuk

\begin{tabular}{|c|c|}
\hline Transkripsi & Terjemahan \\
\hline $\begin{array}{l}\text { A'udzu billahi minasy syaitonir } \\
\text { rojiim }\end{array}$ & $\begin{array}{l}\text { Aku berlindung kepada Allah dari } \\
\text { godaan setan yang terkutuk }\end{array}$ \\
\hline Bismillaahirrrahmaanirrahiim & $\begin{array}{l}\text { Dengan menyebut nama Allah } \\
\text { Yang Maha Pengasih lagi Maha } \\
\text { Penyayang }\end{array}$ \\
\hline $\begin{array}{l}\text { Baju aing, tiung aing, sapatu } \\
\text { aing...(sebutkeun kabeh nu } \\
\text { dipake) }\end{array}$ & $\begin{array}{l}\text { Baju aku, kerudung aku, sepatu } \\
\text { aku... (sebutkan semua yang } \\
\text { dipakai) }\end{array}$ \\
\hline anu asa dipupul bayu ka sia & $\begin{array}{l}\text { yang membuatmu merasa diterpa } \\
\text { angin }\end{array}$ \\
\hline Sing & Melilitlah pada isi perutmu \\
\hline Sing & atimu \\
\hline $\begin{array}{l}\text { Sing ngajentul kana jajantung } \\
\text { sia }\end{array}$ & da jantungmu \\
\hline Sing ngahuleng kana a & amu \\
\hline Tipe & kau impikan \\
\hline Ti beurang aing ku sia karasa & Saat siang aku kau rasakan \\
\hline $\begin{array}{l}\text { Mangka welas asih ka badan } \\
\text { aing sajagat buana }\end{array}$ & $\begin{array}{l}\text { Berbelaskasihlah pada } \\
\text { sejagad raya }\end{array}$ \\
\hline
\end{tabular}

Jangjawokan Paranti Diacuk berfungsi sebagai penambah pesona seorang gadis dari pakaian yang dikenakannya. Jangjawokan ini dirapalkan sebelum berpakaian. Caranya, pegang semua baju (bawahan, atasan, kerudung, sepatu, dan sebagainya), rapalkan jangjawokan dengan bergumam dan menyebut semua baju yang dipegang dalam mantra, kemudian meniupnya setelah selesai mengucap "mangka welas asih ka badan aing sajagat buana." Setelah dimantrai, baju tersebut dipakai sebagaimana biasanya. Menurut penyampai, pakaian yang melekat di tubuh si gadis niscaya akan terlihat pantas melekat padanya dan enak dipandang. 


\section{B. Jangjawokan Wedak Wangi (Mantra Bedak Wangi)}

Tabel 2. Jangjawokan Wedak Wangi

\begin{tabular}{|c|c|}
\hline Transkripsi & Terjemahan \\
\hline $\begin{array}{l}\text { A'udzu billahi minasy syaitonir } \\
\text { rojiim }\end{array}$ & $\begin{array}{l}\text { Aku berlindung kepada Allah dari } \\
\text { godaan setan yang terkutuk }\end{array}$ \\
\hline Bismillaahirrrahmaanirrahiim & $\begin{array}{l}\text { Dengan menyebut nama Allah } \\
\text { Yang Maha Pengasih lagi Maha } \\
\text { Penyayang }\end{array}$ \\
\hline Wedak aing wedak wangi & Bedak aku bedak wangi \\
\hline Kaelenga lenga lengi & Kaelenga lenga lengi \\
\hline $\begin{array}{l}\text { Kiteja ngabentrang kaya datang } \\
\text { na tarang }\end{array}$ & Kiteja memancar di dahi \\
\hline $\begin{array}{l}\text { Kuwung-kuwung melengkung na } \\
\text { irung }\end{array}$ & Bianglala melengkung di hidung \\
\hline Na pipi kawas katumbiri jadi & Di pipi seperti lengkungan pelangi \\
\hline $\begin{array}{l}\text { Cur mancur cahya nurbuwat } \\
\text { ku kersaning Allah ka badan } \\
\text { aing }\end{array}$ & $\begin{array}{l}\text { Memancarlah cahaya nurbuwat } \\
\text { atas kehendak Allah ke badan aku }\end{array}$ \\
\hline
\end{tabular}

Menurut penuturan informan, ketika masih gadis ia hanya perlu mengusap bedak di wajah tanpa menambahkan lipstik maupun produk perawatan kulit (skincare) seperti halnya perempuan masa kini. Maka dari itu, Jangjawokan Wedak Wangi cukup dirapalkan pada bedak yang akan digunakan. Jangan lupa selesai merapal jangjawokan meniupkannya ke permukaan bedak agar khasiatnya lebih ampuh. Informan percaya bahwa perempuan, khususnya gadis, yang memiliki mantra ini wajahnya akan memancarkan cahaya nurbuwat atas kuasa Allah sehingga dikasihi orang-orang.

C. Jangjawokan Sisir Suri (Sebelum Menyisir Rambut)

Tabel 3. Jangjawokan Sisir Suri

\begin{tabular}{|c|c|}
\hline Transkripsi & Terjemahan \\
\hline $\begin{array}{l}\text { A'udzu billahi minasy syaitonir } \\
\text { rojiim }\end{array}$ & $\begin{array}{l}\text { Aku berlindung kepada Allah dari } \\
\text { godaan setan yang terkutuk }\end{array}$ \\
\hline Bismillaahirrrahmaanirrahiim & $\begin{array}{l}\text { Dengan menyebut nama Allah } \\
\text { Yang Maha Pengasih lagi Maha } \\
\text { Penyayang }\end{array}$ \\
\hline Sisir aing sisir suri & Sisir aku sisir ratu \\
\hline Sisir suri ti Raja Mc & Sisir ratu dari Raja Mantri \\
\hline Nu bogoh saewon-ewon & Yang cinta beribu-ribu \\
\hline
\end{tabular}

Jangjawokan Sisir Suri diucapkan sebelum menyisir rambut. Caranya, pegang sisir dengan tangan kanan, kemudian tempelkan sisir di puncak kepala sambil merapal mantra. Mantra ini berkhasiat memberi energi positif pada benda yang akan dipakai menyisir rambut. Bagi perempuan rambut adalah mahkota. Pemilik jangjawokan memiliki pandangan bahwa rambut harus diperlakukan layaknya mahkota seorang ratu, seperti halnya yang tersirat dari teks Jangjawokan Sisir Suri : sisir ratu. 
D. Jangjawokan Rambut Suci (Mantra Rambut Suci)

Tabel 4. Jangjawokan Rambut Suci

\begin{tabular}{|c|c|}
\hline Transkripsi & Terjemahan \\
\hline $\begin{array}{l}\text { A'udzu billahi minasy syaitonir } \\
\text { rojiim }\end{array}$ & $\begin{array}{l}\text { Aku berlindung kepada Allah dari } \\
\text { godaan setan yang terkutuk }\end{array}$ \\
\hline Bismillaahirrrahmaanirrahiim & $\begin{array}{l}\text { Dengan menyebut nama Allah } \\
\text { Yang Maha Pengasih lagi Maha } \\
\text { Penyayang }\end{array}$ \\
\hline Rambut & aku rambut suci \\
\hline tikel rasa & Rar \\
\hline Rasa sia rasa aku & aku \\
\hline indah ka aku & Ras \\
\hline Ti peuting aing ku sia kaimpi & npikan \\
\hline Ti beurang aing ku sia karasa & Saat siang aku kau rasakan \\
\hline $\begin{array}{l}\text { Mangka welas asih ka badan } \\
\text { aing sajagat buana }\end{array}$ & $\begin{array}{l}\text { Berbelaskasihlah pada } \\
\text { sejagad raya }\end{array}$ \\
\hline
\end{tabular}

Setelah merapal Jangjawokan Sisir Suri, sisirlah rambut perlahan sambil mengucapkan Jangjawokan Rambut Suci sebanyak satu kali pada sisiran pertama. Mantra ini dipercaya dapat memancarkan pesona kecantikan seorang gadis dari rambutnya. Jangjawokan Rambut Suci sangat dianjurkan untuk dipakai gadis yang sedang mencari jodoh atau menarik perhatian laki-laki yang dicintainya.

E. Jangjawokan Paranti Dicucuk Sanggul (Mantra Berkonde)

Tabel 5. Jangjawokan Paranti Dicucuk Sanggul

\begin{tabular}{|c|c|}
\hline skripsi & Terj \\
\hline $\begin{array}{l}\text { A'udzu billahi minasy syaitonir } \\
\text { rojiim }\end{array}$ & $\begin{array}{l}\text { Aku berlindung kepada Allah } \\
\text { godaan setan yang terkutuk }\end{array}$ \\
\hline Bismillaahirrrahmaanirrahiim & $\begin{array}{l}\text { Dengan menyebut nama Allah } \\
\text { Yang Maha Pengasih lagi Maha } \\
\text { Penyayang }\end{array}$ \\
\hline $\begin{array}{l}\text { Cucuk Sanggul (jepit, panitih, } \\
\text { jeung sajabana) aing nu asa }\end{array}$ & $\begin{array}{l}\text { Konde (jepit rambut, peniti, dan } \\
\text { sebagainya) } \quad \text { aku } \quad \text { yang }\end{array}$ \\
\hline dipupul bayu ka sia & rpa angin \\
\hline Sing nyusumping kana at & imu \\
\hline Sing meulit kar & $\mathrm{mu}$ \\
\hline $\begin{array}{l}\text { Sing ngajentul kana jajantung } \\
\text { sia }\end{array}$ & gmu \\
\hline Sing & \\
\hline Ti peuting aing & ikan \\
\hline Ti beuran & kau rasakan \\
\hline $\begin{array}{l}\text { Mangka welas asih ka badan } \\
\text { aing sajagat buana }\end{array}$ & $\begin{array}{l}\text { Berbelaskasihlah pada } \\
\text { sejagad raya }\end{array}$ \\
\hline
\end{tabular}


Menurut informan, perempuan Sunda di Desa Karangjaya pada masa lampau berbusana kabaya (kebaya) dan samping (kain lilit bercorak batik), serta melengkapinya dengan sanggul berkonde. Cucuk sanggul (konde) dianggap sebagai pemanis riasan rambut dan memancarkan keanggunan. Konde biasanya terbuat dari logam mulia maupun bunga bertangkai.

Jangjawokan Paranti Dicucuk Sanggul dirapalkan sebagai penutup Jangjawokan Paranti Dangdan. Mantra diucapkan bersamaan dengan menancapkan konde. Sama halnya dengan Jangjawokan Rambut Suci, mantra ini sangat dianjurkan untuk dipakai gadis yang sedang mencari jodoh atau menarik perhatian laki-laki yang dicintainya.

Seiring dengan perkembangan mode, Jangjawokan Paranti Dicucuk Sanggul mengalami pergeseran fungsi. Gadis-gadis Desa Karangjaya pada masa kini tidak lagi mengenakan kabaya, samping, dan bersanggul untuk pakaian sehari-hari, hanya pada acara-acara tertentu saja. Meskipun demikian, jangjawokan ini tetap eksis dipergunakan untuk berdandan sehari-hari karena fungsi mantra untuk konde ditambah objeknya dengan "segala aksesoris yang melekat di rambut" seperti jepit rambut, peniti, mahkota, dan sebagainya.

Performance Jangjawokan Paranti Dangdan mengandung unsur aktif dan pasif. Unsur aktif, menurut Albert B. Lord, lebih terfokus pada proses memori, yang dengan bekal kreativitas memungkinkan seseorang untuk merekonstruksi atau mereorganisasi terhadap pengetahuan sebelumnya. Informan yang dalam penelitian ini berperan sebagai pemilik dan penyampai mantra, ia mengingat, mempraktikkan, dan menurunkan jangjawokan berikut adab-adabnya secara lengkap kepada pewaris. Pemilik jangjawokan pun tidak hanya mewariskan mantra dan adab-adabnya apa adanya, melainkan ada beberapa bagian yang disesuaikan dengan kondisi masa kini. Sementara itu, unsur pasif berkaitan dengan penyimpanan memori kata per kata yang berarti lebih terfokus pada isi memori. Unsur pasif dalam performance mantra ini mengacu pada isi jangjawokan tersebut yang harus diucapkan maupun diwariskan secara utuh tanpa kurang satu kata pun. Pemilik sekaligus penyampai jangjawokan ini percaya bahwa jika hilang satu kata saja atau urutan lariknya terbalik maka daya magisnya akan berkurang.

\section{(2) Transmisi Jangjawokan Paranti Dangdan (Jangjawokan untuk Berdandan)}

Performance berkaitan erat dengan trasmisi. Ketika seseorang melakukan performance suatu sastra lisan, saat itu pula ia sedang menciptakan kembali dan mewariskan sastra lisan tersebut kepada khalayak. Demikian pula yang terjadi pada saat Jangjawokan Paranti Dangdan dirapalkan berikut adab-adabnya di hadapan calon pewaris.

Jangjawokan Paranti Dangdan tidak diwariskan sembarangan. Ada beberapa syarat seseorang dinilai layak mewarisi jangjawokan ini, di antaranya :

a) berjenis kelamin perempuan;

b) memiliki hubungan kekerabatan dengan pemilik jangjawokan; 
c) sudah cukup umur untuk menerima transmisi;

d) sehat jasmani dan rohani;

e) sanggup memenuhi syarat-syarat kepemilikan jangjawokan;

f) dan dinilai membutuhkan jangjawokan untuk perisai diri.

Jangjawokan Paranti Dangdan hanya diwariskan kepada perempuan yang memiliki hubungan keluarga, misalnya dari ibu ke anak perempuan, nenek ke cucu perempuan, bibi ke keponakan perempuan. Pewarisan jangjawokan pun tidak sembarangan. Tidak semua perempuan dalam keluarga tersebut dapat mewarisinya. Pemilik jangjawokan dapat memilih calon pewaris berdasarkan keakraban hubungan, kepercayaan, rasa kasih, maupun apabila diminta secara serius. Contohnya, seorang bibi yang merasa kasihan pada keponakan perempuannya yang sudah berusia matang tetapi belum menemukan jodoh atau belum ada laki-laki yang tertarik padanya, Ia menduga bahwa hal tersebut disebabkan oleh magic kiriman orang lain agar gadis itu selalu terlihat tidak menarik sehingga sulit memperoleh pasangan. Selain itu, ada pula perempuan yang diwarisi jangjawokan ini berdasarkan keakraban hubungan dan kepercayaan. Pemilik jangjawokan menurunkannya dengan sukarela tanpa imbalan apapun. Walaupun demikian, tidak semua pewaris memakainya dengan berbagai alasan : tidak mempercayainya, menganggap kuno, tidak praktis, tidak rasional, khawatir berseberangan dengan akidah agama, maupun tidak sanggup memenuhi persyaratan.

Menurut penuturan informan, ia mewarisi jangjawokan dari ibu dan neneknya ketika berusia tujuh tahun. Pada waktu itu informan hanya tahu sekilas saja, barulah saat beranjak remaja informan menerima secara utuh Jangjawokan Paranti Dangdan. Pewaris dapat dikatakan sempurna mewarisi mantra tersebut apabila telah menunaikan semua syarat dan pameuli. Pameuli adalah syarat wajib untuk menebus atau membeli jangjawokan, biasanya dengan ritual tertentu.

Sebelum pemilik jangjawokan mewariskan mantra secara khusus kepada pewaris, ada beberapa syarat maupun ritual yang harus dijalani pewaris, yaitu:

a) Mandi kembang

Mandi kembang merupakan ritual pertama dalam pewarisan Jangjawokan Paranti Dangdan. Bunga yang dipakai dalam ritual ini harus berjumlah ganjil, minimal tiga dan paling baik tujuh. Jenis bunga harus kembang baheula (bunga yang biasa ditanam pada zaman dahulu, bukan bunga hasil perkawinan silang atau rekayasa genetika) seperti kingkilaban putih, cempaka, asoka, kembang ros (mawar), melati, kenanga, dan sedap malam. Pemilik jangjawokan memandikan calon pewaris di tujuh sumur yang berbeda pada waktu pagi sebelum sumur tersebut dipakai orang lain. Adapun sumur yang dianggap paling baik untuk mandi kembang adalah mata air, bukan sumur buatan. Tetapi, saat ini di sekitar Desa Karangjaya sulit ditemukan mata air. Melihat keadaan itu, ritual mandi diperbolehkan menggunakan sumur buatan dan ada keringanan hanya memakai tiga sumur. Ritual mandi kembang ini dipercaya dapat memancarkan aura positif dan menghilangkan aura negatif.

b) Pembersihan diri 
Setelah mandi di sumur terakhir, ada satu tahap ritual lagi yaitu pembersihan diri. Calon pewaris diharuskan buang air kecil dan menampungnya sedikit di wadah. Pemilik jangjawokan kemudian mengucap ta'awudz, basmallah, dan memohon kepada Allah (dalam bahasa Sunda halus) agar dihilangkan segala keburukan yang disebabkan gangguan setan maupun kiriman magic ringan dari orang dengki yang selama ini tidak disadari calon pewaris. Setelah pemilik jangjawokan meniup secawan kecil air seni tersebut, calon pewaris meminumnya sampai habis. Dalam kepercayaan masyarakat Sunda di sekitar Desa Karangjaya percaya bahwa air seni (terutama air seni pertama di pagi hari) merupakan penawar magic paling ampuh. Ritual meminum air seni pun dianjurkan dilakukan secara rutin, terlebih apabila tinggal di wilayah yang rawan santet.

Calon pewaris jangjawokan yang sudah menyelesaikan dua ritual wajib tersebut barulah dianggap pantas mewarisi jangjawokan secara utuh. Pewarisan ini bersifat tertutup, tidak boleh ada pihak lain (terutama laki-laki, termasuk ayah dan saudara kandung) yang melihat. Pemilik atau penyampai jangjawokan akan mengucapkan satu per satu mantra yang hendak diwariskannya dengan lirih agar tidak terdengar orang lain. Apabila ada orang lain yang melihat maupun mendengar prosesi tersebut maka jangjawokan akan cambal (tidak berkhasiat) bagi pewaris dan transmisi dianggap gagal. Selama transmisi berlangsung, pewaris diperbolehkan mencatatnya dengan syarat apabila sudah berhasil dihapalkan harus menghancurkan catatan itu agar tidak ditemukan orang lain. Apabila catatan ditemukan orang lain maka mantra akan cambal bagi pewaris dan penemulah yang malah dapat langsung memperoleh khasiatnya tanpa melalui proses ritual dan menebus pameuli. Oleh karena itu, atas permintaan informan, teks mantra dalam penelitian ini ada bagian yang dihilangkan untuk menjaga kerahasiaan dan kesakralannya.

Ada tahap akhir untuk penyempurnaan kepemilikan jangjawokan. Setelah pewaris berhasil menghapal seluruh mantra, pewaris diwajibkan menebus pameuli yaitu puasa. Menurut informan, leluhurnya ada yang sampai berhasil menebus pameuli dengan puasa mati geni (puasa nonstop) selama 40 hari 40 malam, sedangkan informan tersebut hanya sanggup menebusnya dengan mati geni tiga hari tiga malam. Mati geni bukan sebatas pameuli mantra, melainkan sebagai tirakat yang berhubungan dengan pembersihan diri, penenang jiwa, berserah kepada Yang Kuasa, mengendalikan hawa nafsu, dan meningkatkan spiritual. Apabila tidak menyanggupi syarat mati geni, pewaris diperbolehkan berpuasa wedalan (puasa pada hari lahir) sebanyak tiga kali maupun tujuh kali berturut-turut seseuai kesanggupan. Tiga atau tujuh kali puasa tidak akan mengurangi khasiat mantra jika menebus pameuli dengan ikhlas dan berniat menggunakan jampe pamake untuk kebaikan. Setelah berhasil menunaikan semua syarat dan ritual, maka pewaris telah sempurna mewarisi mantra dan diperbolehkan mewariskannya kepada orangorang yang dikehendakinya. Apabila suatu saat pewaris ingin melepaskan diri dari kepemilikan mantra, pewaris hanya perlu merapalkan semua jangjawokan yang dimilikinya saat buang air besar. 


\section{SIMPULAN}

Khazanah sastra daerah dan sastra lisan di Indonesia sangat kaya akan tradisi puisi, khususnya jenis puisi formulaik. Mantra, contohnya. Mantra dikenal secara luas di Indonesia, khususnya dalam masyarakat Sunda seperti di wilayah Desa Karangjaya Kabupaten Pangandaran. Di tengah perkembangan zaman yang semakin pesat, mantra masih tergolong eksis di Desa Karangjaya. Bukan hanya orang-orang tua saja yang mengamalkan mantra dalam kehidupan sehari-hari, bahkan gadis-gadis muda pun masih ada yang memiliki dan mempercayainya. Ada beberapa hal yang menyebabkan Jangjawokan Paranti Dangdan masih eksis di Desa Karangjaya : kewaspadaan dan kekhawatiran atas gangguan magic jahat yang juga eksis di lingkungan sekitar, keinginan untuk tampil menarik dan dikasihi, serta sebagai upaya memudahkan mencari jodoh bagi yang masih lajang. Pengguna Jangjawokan Paranti Dangdan percaya bahwa produk perawatan kulit, riasan wajah, dan pakaian yang pantas hanya untuk memperindah secara ragawi tetapi tidak dapat dijadikan perisai diri. Meskipun mantra tersebut masih banyak dipergunakan, bukan berarti semua perempuan di Desa Karangjaya mempercayai khasiatnya. Di antaranya ada yang pernah diwarisi mantra tetapi tidak menebusnya, mengetahui eksistensinya tetapi tidak tertarik untuk nyungsi (mempelajari), dan ada pula yang tidak mengetahuinya. Sedangkan alasan kelompok perempuan yang tidak menggunakan jangjawokan di antaranya adalah tidak mempercayainya, menganggap kuno, tidak praktis, tidak rasional, khawatir berseberangan dengan akidah agama, maupun tidak sanggup memenuhi persyaratan. 


\section{DAFTAR PUSTAKA}

Dananjaya, James. (1991). Folklor Indonesia Ilmu Gosip, Dongeng, dan Lain-Lain. Jakarta: Percetakan PT Temprint.

Endraswara, Suwardi. (2009). Metodologi Penelitian Folklor Konsep, Teori, dan Aplikasi. Yogyakarta: FBS Universitas Negeri Yogyakarta.

Finnegan, Ruth. (1992). Oral Tradition and the Verbal Arts. London: Routledge.

Lord, Albert B. (1981). The Singer of Tales. Cambridge: Harvard University Press.

Muhazetty, B. (2017). "Mantra dalam Budaya Jawa (Suntingan Teks Jawa dan Kajian Pragmatik)" Semarang: Universitas Diponegoro. (Tesis).

Misnawati, M. P., \& Anwarsani, S. P. (2000). Teori Stuktural Levi-Strauss dan Interpretatif Simbolik untuk Penelitian Sastra Lisan. GUEPEDIA.

Misnawati, M., Poerwadi, P., \& Rosia, F. M. (2020). Struktur Dasar Sastra Lisan Deder. Pedagogik: Jurnal Pendidikan, 15(2), 44-55.

Nababan, V. D., Diman, P., \& Cuesdeyeni, P. (2021). GAYA BAHASA PERBANDINGAN DALAM NOVEL GARIS WAKTU KARYA FIERSA BESARI. ENGGANG: Jurnal Pendidikan, Bahasa, Sastra, Seni, dan Budaya, 2(1), 67-78.

Nazriani. (2012). "Mantra dalam Upacara Pesondo (Kajian Struktur Teks, Konteks Penuturan, Proses Penciptaan, dan Fungsi serta Kemungkinan Pemanfaatannya sebagai Bahan Ajar Sastra di SMA).” Bandung: Universitas Pendidikan Indonesia. (Tesis).

Perdana, I., \& Misnawati, M. P. (2019). Cinta dan Bangga Berbahasa Indonesia Di Perguruan Tinggi. SPASI MEDIA.

Ramadhan, Vazareyno. (2016). "Peranan Magis Jangjawokan Nyadarkeun dalam Seni Tradisi Reak Helaran di Kecamatan Cibiru Kota." Bandung: Universitas Pendidikan Indonesia. (Skripsi).

Rusyana, Yus. (1970). Bagbagan Puisi Mantra Sunda. Bandung: Proyek Penelitian Pantun dan Folklor Sunda.

Taum, Yoseph Yapi. (2011). Studi Sastra Lisan Sejarah, Teori, Metode, dan Pendekatan Disertai Contoh Penerapannya. Yogyakarta: Penerbit Lamalera. 